\title{
A Preliminary Cohort Study Assessing Routine Blood Analyte Levels and Neurological Outcome after Spinal Cord Injury
}

\author{
Sharon J. Brown, ${ }^{1,2}$ Gabriel M.B. Harrington,, ${ }^{1,2}$ Charlotte H. Hulme, ${ }^{1,2}$ Rachel Morris, ${ }^{2}$ Anna Bennett, ${ }^{3}$ \\ Wai-Hung Tsang, ${ }^{2}$ Aheed Osman, ${ }^{2}$ Joy Chowdhury, ${ }^{2}$ Naveen Kumar, ${ }^{2}$ and Karina T. Wrightt,2
}

\begin{abstract}
There is increasing interest in the identification of biomarkers that could predict neurological outcome following a spinal cord injury (SCI). Although initial American Spinal Injury Association (ASIA) Impairment Scale (AIS) grade is a good indicator of neurological outcome, for the patient and clinicians, an element of uncertainty remains. This preliminary study aimed to assess the additive potential of routine blood analytes following principal component analysis (PCA) to develop prognostic models for neurological outcome following SCI. Routine blood and clinical data were collected from SCI patients $(n=82)$ and PCA used to reduce the number of blood analytes into related factors. Outcome neurology was obtained from AIS scores at 3 and 12 months post-injury, with motor (AIS and total including all myotomes) and sensory (AIS, touch and pain) abilities being assessed individually. Multiple regression models were created for all outcome measures. Blood analytes relating to "liver function" and "acute inflammation and liver function" factors were found to significantly increase prediction of neurological outcome at both 3 months (touch, pain, and AIS sensory) and at 1 year (pain, $R^{2}$ increased by 0.025 and total motor, $R^{2}$ increased by 0.016 ). For some models "liver function" and "acute inflammation and liver function" factors were both significantly predictive, with the greatest combined $R^{2}$ improvement of 0.043 occurring for 3 month pain prediction. These preliminary findings support ongoing research into the use of routine blood analytes in the prediction of neurological outcome in SCI patients.
\end{abstract}

Keywords: blood; biomarker; neurology; outcome; SCI

\section{Introduction}

$\mathbf{R}$ ELATIVELY FEW STUDies have sought to identify prognostic biomarkers for spinal cord injury (SCI), although in recent years more early/discovery phase work in this research area has been published. ${ }^{1-4}$ However, this field of study is considered to be in its infancy, and no biomarkers to date have been examined routinely in SCI patients. ${ }^{5}$ Importantly, any potential new biomarkers must demonstrate their utility in the context of the currently used prognostic indicators, of which the severity of the initial injury is the most indicative of long-term neurological recovery; however, age, medical history/medication, polytrauma, and gender are also relevant. ${ }^{6,7}$ Further, care must be taken to consider confounding variables such as diet, obesity, diabetes, and smoker status. $^{8-10}$

There is a growing appreciation of the value of analyzing routinely collected patient samples for relevant biomarkers in various fields, such as breast cancer, liver fibrosis, osteoporosis, and cardiovascular disease. ${ }^{1-14}$ However, to our knowledge, there are no comprehensive studies examining the utility of multiple routinely measured biomarkers in SCI patients, despite the success of such techniques in the fields of Alzheimer's disease, cancer, and osteoarthritis. ${ }^{15-17}$ Routinely measured blood biomarkers include indicators of organ function, bone profile measures, infection and inflammation, nutritional status, and overall blood counts. In other neurological conditions, some of these routinely measured biomarkers have been associated with long-term neurological outcomes. For example, serum albumin concentrations are routinely measured to determine liver function and/or dietary status; however, altered albumin concentrations both during ${ }^{18}$ and in the acute phase following ischemic stroke ${ }^{19}$ have been associated with neurological state post-stroke. Moreover, serum albumin levels have been found to relate to outcome following traumatic brain injury (TBI), ${ }^{20}$ intravenous immunoglobulin-treated Guillain-Barre Syndrome, ${ }^{21}$ and amyotrophic lateral sclerosis (ALS), ${ }^{22}$ in addition to serum creatinine concentrations, which have been shown to correlate with ALS outcome. $^{22}$

This study aims to assess routinely collected blood samples taken within 2 weeks of SCI (acute setting) and compare samples across patients with their neurological outcomes at 3 and 12 months

\footnotetext{
${ }^{1}$ Institute of Science and Technology in Medicine (ISTM), Keele University, Keele, United Kingdom.

${ }^{2}$ Robert Jones and Agnes Hunt Orthopaedic Hospital, Oswestry, Shropshire, United Kingdom.

${ }^{3}$ Life Sciences, University of Chester, Chester, Cheshire, United Kingdom.
}

(C) Sharon J. Brown et al., 2019; Published by Mary Ann Liebert, Inc. This Open Access article is distributed under the terms of the Creative Commons Attribution Noncommercial License (http://creativecommons.org/licenses/by-nc/4.0/) which permits any noncommercial use, distribution, and reproduction in any medium, provided the original author(s) and the source are credited. 
Table 1. Summary of Clinical Information FOR THE PATIENT COHORT

\begin{tabular}{|c|c|}
\hline & SCI Patients (n) \\
\hline Age (mean $\pm \mathrm{SD}$ ) $44.4 \pm 17.2$ years & 82 \\
\hline Males & 60 \\
\hline Females & 22 \\
\hline \multicolumn{2}{|l|}{ Level of injury: } \\
\hline Cervical & 47 \\
\hline Thoracic & 27 \\
\hline Lumbar & 8 \\
\hline \multicolumn{2}{|l|}{ Injury level: } \\
\hline Above L1 & 72 \\
\hline At $L 1$ & 6 \\
\hline Below L1 & 2 \\
\hline Neurologically intact & 2 \\
\hline \multicolumn{2}{|l|}{ Initial AIS score: } \\
\hline A & 34 \\
\hline$B$ & 9 \\
\hline$C$ & 26 \\
\hline$D$ & 11 \\
\hline$E$ & 2 \\
\hline \multicolumn{2}{|l|}{ Outcome AIS score: } \\
\hline A & 29 \\
\hline$B$ & 7 \\
\hline$C$ & 15 \\
\hline$D$ & 29 \\
\hline$E$ & 2 \\
\hline Complete & 34 \\
\hline Incomplete & 46 \\
\hline Neurologically intact & 2 \\
\hline Tetraplegic & 46 \\
\hline Paraplegic & 34 \\
\hline \multicolumn{2}{|l|}{ Improvers: } \\
\hline$A \rightarrow B$ & 3 \\
\hline$A \rightarrow C$ & 2 \\
\hline$B \rightarrow C$ & 2 \\
\hline$B \rightarrow D$ & 3 \\
\hline$C \rightarrow D$ & 15 \\
\hline CCS patients & 11 \\
\hline Vertebral fracture & 67 \\
\hline Surgery required following injury & 34 \\
\hline Initial infection & 7 \\
\hline Diabetes & 8 \\
\hline Pressure sores & 9 \\
\hline \multicolumn{2}{|l|}{ *Comorbidities: } \\
\hline None & 60 \\
\hline One & 11 \\
\hline Two & 7 \\
\hline Three & 3 \\
\hline \multicolumn{2}{|l|}{ **Smoker: } \\
\hline No & 47 \\
\hline Previous & 13 \\
\hline Yes & 20 \\
\hline \multicolumn{2}{|l|}{ **Alcohol: } \\
\hline No & 16 \\
\hline Yes & 64 \\
\hline \multicolumn{2}{|c|}{ Medications with potential to impact blood analytes: } \\
\hline No & 34 \\
\hline Yes, but no known impact & 18 \\
\hline Yes, and potential to impact & 30 \\
\hline
\end{tabular}

(continued)
TABLE 1. (CONTINUED)

\begin{tabular}{ll}
\hline & SCI Patients (n) \\
\hline Impact of existing ailments on blood samples: & \\
None & 46 \\
One ailment & 19 \\
Two or more ailments & 17 \\
*Polytrauma & 47 \\
Non-polytrauma & 34 \\
British & 70
\end{tabular}

*Asterisks indicate that information regarding these parameters were unavailable for one $(*)$ or two $(* *)$ of the patients respectively. Characteristics in italics were not inputted into the multiple regression models.

SCI, spinal cord injury; SD, standard deviation; AIS, American Spinal Injury Association (ASIA) Impairment Scale; CCS, central cord syndrome.

post-injury. These data, in combination with the aforementioned known prognostic indicators (baseline neurology, age, gender, diabetes status), will form the basis of a prognostic model, similar to those developed for TBI, ${ }^{23}$ that can be refined in future work.

\section{Methods}

\section{Summary of patients included in study}

We retrospectively studied records from 99 patients who had been admitted to the Midlands Centre for Spinal Injuries (MCSI) between 1980 and 2017. These patients were from a cohort who had previously consented for their patient records to be accessed as part of two other ethically approved studies (National Research Ethics Service [NRES] Committee North West Liverpool East [11/NW/0876] and NRES Committee West Midlands, Staffordshire [13/WM/0158]). Seventeen patients were excluded: one patient because of previous acute myeloid leukemia, the remaining because of incomplete data on initial and 3 month follow-up International Standards for Neurological Classification of SCI (ISNCSCI) AIS (American Spinal Injury Association [ASIA] Impairment Scale) scores, or their injuries being non-traumatic.

Eighty-two SCI patients (age range 17-81 years) whose initial blood samples were taken on average at $7 \pm 4$ days following traumatic injury were included in the statistical analyses (Table 1). The blood data were reviewed, and information regarding full blood counts, urea/electrolytes, liver function, bone profile measures including magnesium, C-reactive protein (CRP), and other parameters such as prothrombin time were recorded (Table S1). Routine blood analyses were conducted in the Haematology and Biochemistry department located at the Robert Jones and Agnes Hunt Orthopaedic Hospital. Hematology analyses were performed on either a Beckman Coulter LH-500 or a Sysmex XN-1000, whereas biochemical analyses used VITROS slides (dry multi-layered chemistry slides) in conjunction with the VITROS 5,1 FS Chemistry System to measure albumin, alanine transaminase (ALT), calcium, creatinine, gamma-glutamyl transferase (GGT), potassium, magnesium, sodium, phosphate, total bilirubin, total protein, and urea.

AIS scores were collated and broken down into muscle function (AIS motor $[\mathrm{M}]$ ) and sensory (AIS Sens) scores with the sensory scores being split further into touch (T) and pain (P) scores. AIS scores for muscle function focus on $10 \mathrm{key}$ muscle groups, ${ }^{24}$ so whenever possible, a functional score for all muscle groups (total M) was collated.

Additional information that could impact on the blood analytes was included in the predictive model analysis. Comorbidities were coded and represented the number that the patient currently had, and included musculoskeletal, respiratory, abdominal, cardiovascular, and mental health issues. The presence of vertebral fractures and the necessity for surgical intervention following injury were 
also recorded. As to whether patients had an infection, diabetes, or pressure sores, were smokers, or had previously smoked and/or drunk alcohol were noted. If the patient had sustained a polytrauma at the time of the SCI, such as other broken bones including additional fractured vertebrae, severe contusions, or burns, this was documented. If the patient was receiving medications in addition to the typical painkillers and anti-stomach acid and anticoagulant preparations received following a SCI, these were recorded and grouped into those that may have influenced blood biomarker outcome such as statins, steroids, certain antibiotics, and antidepressants, and those that would likely not.

\section{Statistical analysis}

Statistical calculations were performed with IBM SPSS Statistics version 24.0 (SPSS Inc., Chicago, IL). Data were assessed for normality using both the Kolmogorov-Smirnov and Shapiro-Wilk tests. As the majority of data were not normally distributed, nonparametric tests were performed. Clinical features with binary outcomes that could potentially influence levels of the various blood biomarkers, such as gender and infection, were assessed via the Mann-Whitney $U$ test (exact, two tailed) whereas features with more than two possible outcomes, such as injury level, were assessed via Kruskal-Wallis. All variables were assessed for significant associations using Kendall's tau for non-parametric rank correlations.

In total, five neurological outcome measures were assessed: total $\mathrm{M}$ (total muscle function), T (touch), $\mathrm{P}$ (pain), AIS M (muscle function focused on key groups), and AIS Sens (sensory function, T and $\mathrm{P}$ combined) at $\sim 3$ and 12 months post-injury, to account for the potential of the blood analytes to predict subtle improvements/worsening in motor or sensory function.

As the number of blood analytes being assessed was relatively high compared with the number of participants, principal component analysis (PCA) was performed to determine the possibility of reducing the number of blood analytes into related factors. Factor analysis via PCA was conducted on both blood analytes and initial neurological measures following removal of any high $(r>0.8)$ or low $(r<0.3)$ correlations via oblique rotation (direct oblimin). The resulting factors were named to reflect their most appropriate biological function.

The potential of individual blood analytes and factors generated from PCA were assessed in combination with compounding clinical factors (Table 1) and either the initial neurological scores (M, T, P, AIS M, and AIS Sens) or the appropriate neurological factor generated from PCA via multiple regression analysis to determine their potential to predict outcome neurology at 3 and 12 months. Values of $p<0.05$ were considered statistically significant. Statistical analyses and $p$ values were not adjusted for multiple testing and should be interpreted accordingly.

\section{Results}

All 82 patients had undergone a traumatic SCI: 33 patients had undergone a fall from a height or step; 29 patients had been involved in a motor vehicle incident (car, motorbike, go-karting); 15 patients were injured during sporting activities (horse riding, climbing, skateboarding, skiing, air sports, cycling, rugby, fairground ride); 4 patients had been struck by a falling weight; and 1 patient had been assaulted.

There were 34 patients classed as ISNCSCI AIS A, 9 patients classed as AIS B, 26 patients classed as AIS C, 11 patients classed as AIS D, and 2 patients classed as neurologically intact following their initial neurological examination following injury. All patients had follow-up neurological scores; 79 patients at $\sim 3$ months and 72 patients at 1 year. Of the 82 patients, 25 were termed "improvers," as their ISNCSCI AIS score improved by at least one level (Table 1).
Seventy-five percent of patients included in the study were males, with most injuries occurring at the cervical level (57\%) and the least number of injuries occurring in the lumbar region (10\%). Most patients (41\%) sustained an AIS A complete injury (for the purposes of this study AIS A improvers were described as complete). The second most common injury was AIS C (32\%). The majority of patients $(56 \%)$ had an incomplete injury and $56 \%$ were tetraplegic. Although $6 \%$ of AIS A patients improved to become AIS B ( $4 \%$ ) or C (2\%), and $2 \%$ of AIS B patients became AIS C, the greatest percentage of improvers occurred in the AIS C group, with $18 \%$ of patients becoming AIS D.

Central cord syndrome (CCS) occurred in 13\% of patients, whereas vertebral fractures were detected in $82 \%$ of patients. Surgery was required in $41 \%$ of cases whereas initial infections $(9 \%)$, diabetes $(10 \%)$, and pressure sore incidences $(11 \%)$ were relatively uncommon. The majority of patients had no comorbidities $(74 \%)$, whereas the remaining had one $(14 \%)$, two $(9 \%)$, or three $(4 \%)$ comorbidities. Of these existing medical conditions, most had no effect on blood analytes $(56 \%)$, whereas medications that could impact on these measures were being taken by just over one third of patients $(37 \%)$. More than half of patients $(58 \%)$ had sustained polytrauma, and the majority had never smoked, whereas $80 \%$ regularly drank alcohol.

Table S1 provides a summary of the neurological scores and various analytes routinely measured in SCI patients on admission. In particular, red blood cell (RBC) measures had a tendency to be lower than the normal range whereas white blood measures tended to be higher. Most electrolytes fell within the normal range, but liver function and bone profile measures tended to be higher, with albumin and total protein levels appearing to be lower than normal values. The inflammatory marker, CRP, was also higher in the majority of SCI patients, in comparison with normal levels.

Assessment of categorical features that could impact on the blood analytes demonstrated typically associated differences with respect to gender on $\mathrm{RBC}$ measures, albumin, total protein, and prothrombin time but also creatinine. Significant differences in RBC measures were also found in patients with CCS or injuries causing tetraplegia compared with paraplegia, different levels of injury or complete versus incomplete injury, vertebral fracture presence, surgical intervention following injury, or with comorbidities. Smoking and alcohol affected red cell distance width, and mean cell haemoglobin, respectively. Urea was found to be significantly different in improvers $(7.2 \pm 2.8 \mathrm{mmol} / \mathrm{L})$ compared with non-improvers $(5.8 \pm 1.8 \mathrm{mmol} / \mathrm{L})$, and was affected by level and presence of vertebral fracture, whereas albumin discriminated among initial AIS grades. CRP was found to be affected by level and severity of injury, surgical intervention, polytrauma and comorbidities, existing ailments, and medications. Calcium levels were affected by patients having diabetes and polytrauma, whereas sodium, which was also affected by diabetes, was impacted by alcohol intake as well. The presence of comorbidities and pressure sores was found to affect potassium levels. ALT, a marker of liver health, was lower in tetraplegics $(58.8 \pm 38.2 \mathrm{u} / \mathrm{L})$ than in paraplegics $(79.7 \pm 61.0 \mathrm{u} / \mathrm{L})$ and was also affected by the patient having had surgery following injury (as were other markers of liver function such as GGT and prothrombin time), smoking, pressure sores, and pre-existing conditions that also affected prothrombin time.

Hematological indices were impacted by surgery (platelets and mononuclear cells), diabetes (neutrophils), and pressure sores (platelets). Surgery also affected creatinine and alkaline phosphatase (AP) levels. Age was also found to be a contributory feature with regard to injury level and severity, vertebral fracture, surgical 


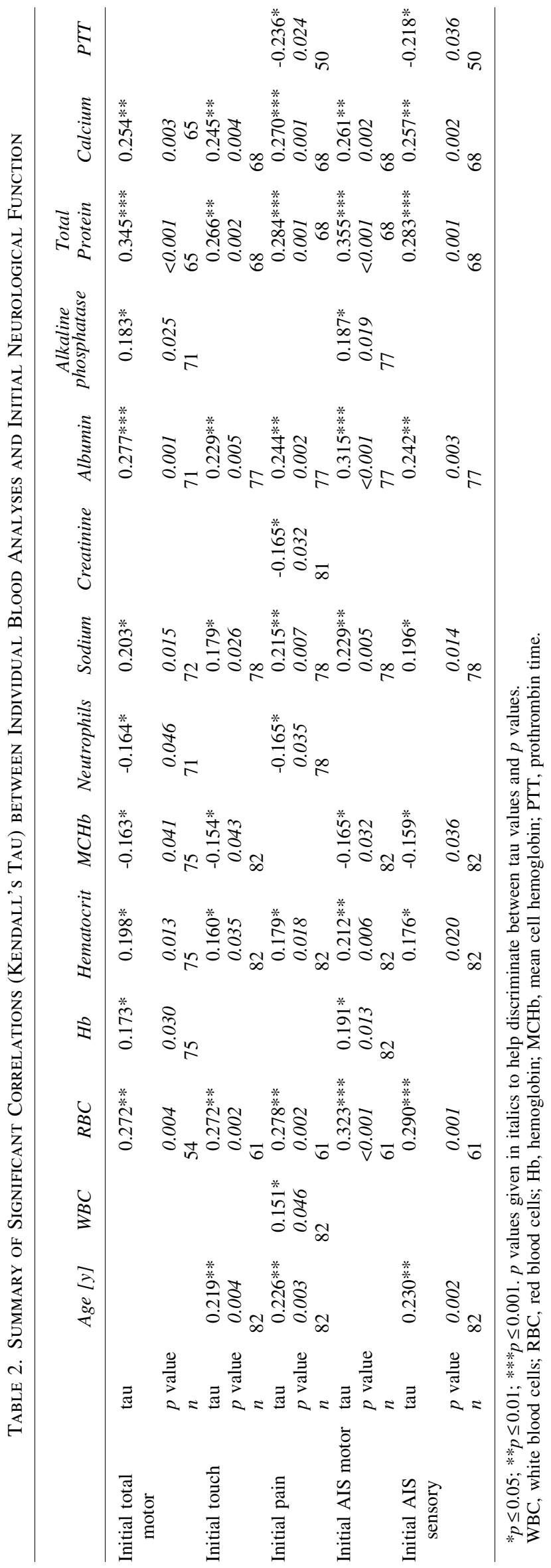

intervention, polytrauma, diabetes, comorbidities, and additional medications. Only seven patients had an initial infection on admission; therefore, significant differences need to be interpreted with caution, but urea, albumin, total protein, ALT, and GGT were found to be different between patients with and without an initial infection.

The various blood analytes were assessed against initial (Table 2) and outcome (Table 3) neurological measures at 3 and 12 months post-injury to determine whether any significant correlations existed. No significant correlations between the initial or outcome neurological scores at 3 and 12 months post-injury and the following blood analytes were found: mean corpuscular volume, red cell distance width, platelets, lymphocytes, mononuclear cells, eosinophils, urea, ALT, total bilirubin, CRP, phosphate, adjusted calcium, magnesium and international normalized ratio (INR).

Thirteen blood analytes correlated with some or all of the initial neurology scores (Table 2). Some blood analytes correlated with only those scores associated with sensory outcome, such as white blood cells (WBC), creatinine, and prothrombin time, whereas others were associated only with muscle function (hemoglobin and AP levels). The remaining measures correlated with both sensory and muscle function, in particular, $\mathrm{RBC}$ measures (RBC, hematocrit and mean cell hemoglobin [MCHb]) and albumin, total protein, sodium, and calcium levels. The strongest correlation occurred between total protein and initial AIS M (Kendall's tau $=0.355, p<0.000$ ).

Table 3 summarizes the significant correlations between the blood analytes and outcome neurology. RBC was the only blood analyte that correlated with all of the outcome measures at both 3 and 12 months post-injury. Hemoglobin, hematocrit, total protein, and calcium correlated with all outcome measures at 3 months. Hemoglobin and hematocrit only correlated with AIS M at 1 year and calcium correlated with $\mathrm{T}$ and AIS Sens at 1 year, whereas total protein correlated with all 1 year outcome measures except for the total M score. Albumin and basophils correlated with all outcome measures at 3 months except for the P score, and basophils also correlated with all outcome measures at 1 year except for the total $\mathrm{M}$ score, whereas at 1 year, albumin only correlated with the muscle function scores (total M and AIS M). Of the electrolytes, sodium and potassium correlated with one neurological outcome at the 3 month time point, AIS M and Total M respectively. GGT only correlated with sensory outcomes at 1 year ( $\mathrm{T}$ and AIS Sens) and age correlated with both sensory and muscle function measures at 3 and 12 months post-injury. The strongest correlation between blood analytes and outcome neurology was between RBC and 1 year AIS $\mathrm{M}$ (Kendall's tau $=0.352, p<0.001$ ).

PCA was conducted to reduce the number of blood analytes for predictive modeling analysis. Initially, correlation matrices were generated for all neurological and blood analyte measures and any measures that had correlation coefficients $>0.8$ were applied to the PCA independently of each other, whereas measures that correlated with all other measures with coefficients $<0.3$ were excluded. High correlations $(>0.8)$ were only found between the initial measures of total M, P, and T (individual measures) with initial AIS M and AIS Sens (combined) scores. The individual measures were put into PCA-I whereas the combined AIS scores were input into PCA-C. The Kaiser-Meyer-Olkin (KMO) measure verified the sampling adequacy for the analysis, $(\mathrm{KMO}=0.693$ and 0.694 for PCA-I and PCA-C respectively) and all KMO values for each measure/analyte was $>0.67$, which is above the acceptable limit of $0.5^{25}$ (analytes that did not reach this limit were omitted from the PCA). Bartlett's test of sphericity was $\chi^{2}(120)=451.075, p<0.001$ and $\chi^{2}(66)=272.967$, $p<0.001$ respectively, indicating that correlations between items 


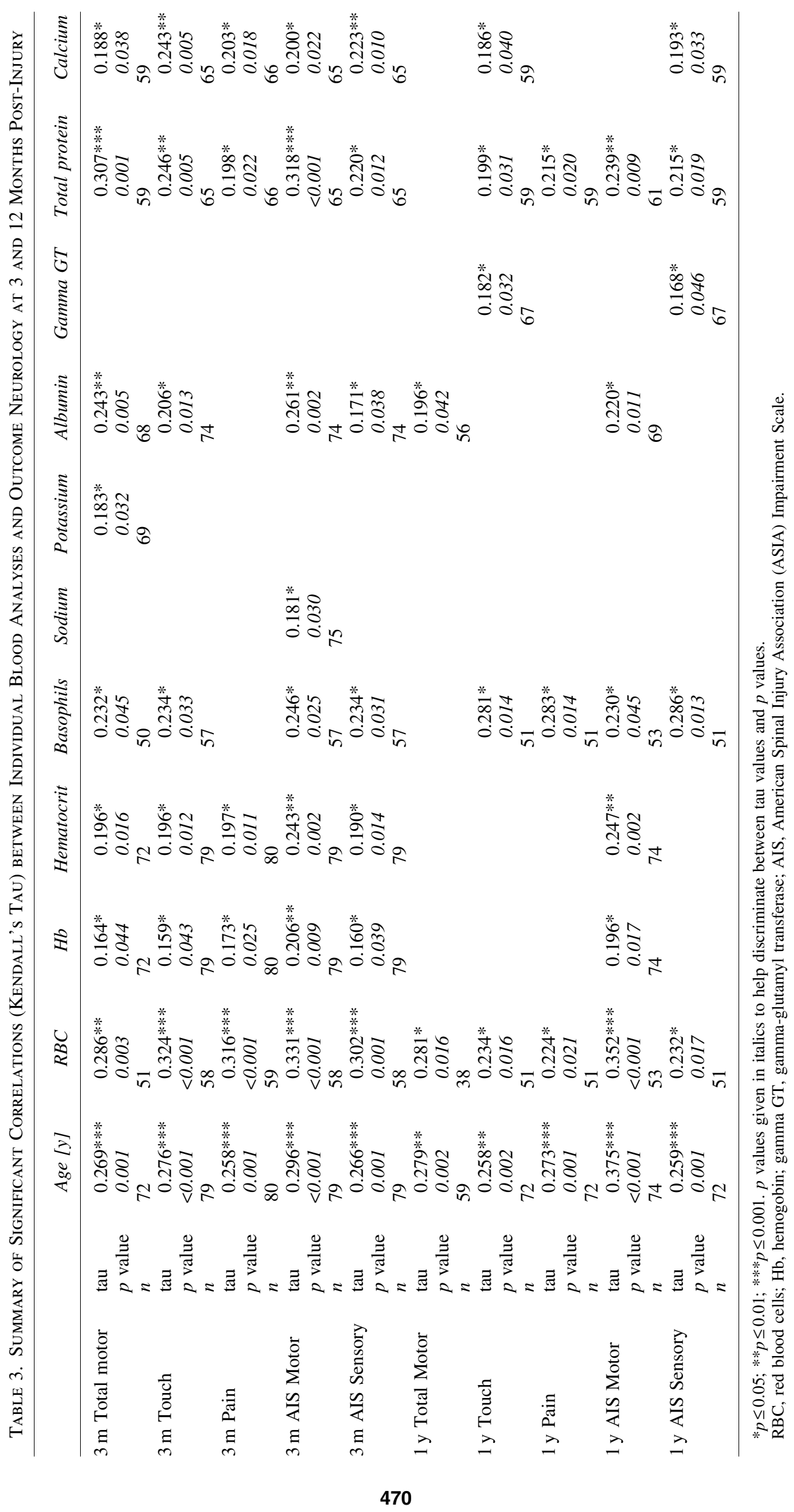




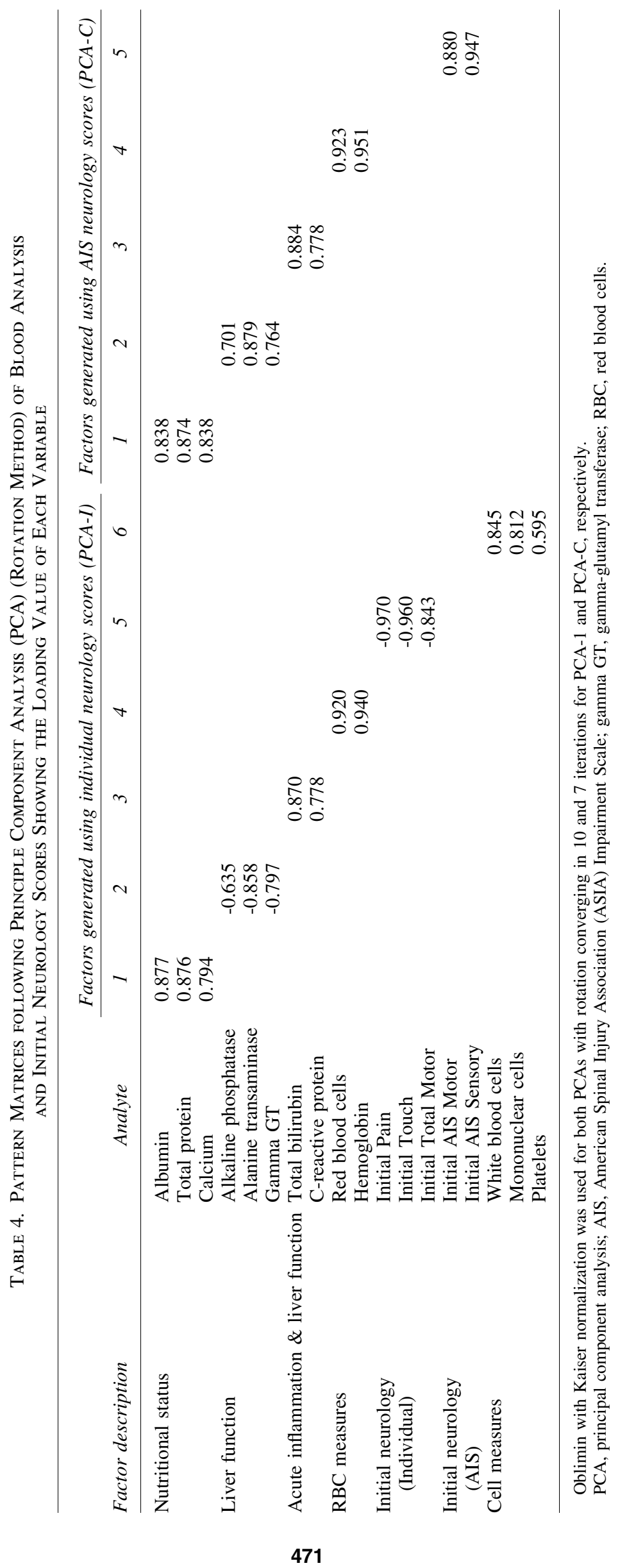


were sufficiently large for PCA. An initial analysis was run to obtain eigenvalues for each factor in the data. Six and five factors for PCA-I and PCA-C, respectively, had eigenvalues above Kaiser's criterion of 1 , and in combination explained $80.02 \%$ and $81.35 \%$ of the variance, respectively. Additionally, scree plots showed inflexions that justified retaining the factors up to 6 and 5. Given the sample size, the convergence of the scree plot, and Kaiser's criterion on both six and five factors for PCA-I and PCA-C respectively, these are the number of factors that were retained in the final analyses.

Table 4 shows the pattern matrices after rotation and provides the loading values for each variable. When initial total $\mathrm{M}, \mathrm{P}$ and $\mathrm{T}$ (PCA-I) were included in the analysis, the items that clustered on the same factors suggested that factor 1 represented "nutritional status," factor 2 represented "liver function," factor 3 represented "acute inflammation and liver function," factor 4 represented "RBC measures," factor 5 represented "initial neurology," and factor 6 represented "cell measures." When initial AIS M and AIS Sens (PCA-C) were used for PCA, only five factors were generated representing the same measures as mentioned, but with no factor 6 representing "cell measures." The resulting contributions of each blood analyte to factors 1-4 were subtly different (except for CRP) when either the individual or the overall AIS scores were input.

Assessment of correlations between the factors generated from PCA-I (Table 4) against outcome neurological measures revealed, as expected, that factor 5 (initial neurology) correlated with all outcome measures at both 3 months and 1 year follow-up (Kendall's tau ranged from 0.53 to $0.69, p<0.001$ for all correlations). Table S2 shows that factor 1, representing "nutritional status," correlated with all outcome neurology measures at 3 months except for P, whereas factor 4, representing "RBC measures," correlated with all outcome neurology measures at 3 months except for 3 month Total M. Factors 1 and 4 also correlated with AIS M at 1 year, but factor 2 "liver function," factor 3 "acute inflammation and liver function," and factor 6 "cell measures" did not significantly correlate with any neurology outcome measure (Table S2).

Factors generated from PCA-C (Table 4) were also correlated with outcome neurology measures and again, factor 5 (initial neurology) correlated with all outcome measures at both 3 and 12 month follow-up (Kendall's tau ranged from 0.53 to 0.88 , $p<0.001$ for all correlations). As found previously, factor 1 , representing "nutritional status," correlated with all outcome neurology measures at 3 months except for $\mathrm{P}$, but factor 4 , representing "RBC measures," correlated with all outcome neurology measures at 3 months (Table S2). As before, factors 1 and 4 correlated with AIS M at 1 year, but factor 2 "liver function" and factor 3 "acute inflammation and liver function" did not significantly correlate with any neurology outcome measures.

Multiple regression models were utilized to produce predictive models of neurological outcome following SCI at $\sim 3$ and 12 months post-injury (Table 5 and Table S3). These models included many of the clinical variables described in Table 1 (all clinical features not in italics); for example: age, gender, injury level, polytrauma, smoking, the existence of additional conditions, and medications that could affect blood analytes. In all predictive models for neurological outcome (Table 5 and Table S3), the main contributing factor was Step 1, "initial neurology" + "constant," ( $R^{2}$ range 0.5-0.766). When factors from PCA-I were used in the predictive model, factors relating to "liver function" and "acute inflammation and liver function" were found to be significant in the predictive models of all sensory neurological outcomes at 3 months
(Table S3). In contrast, no factors relating to the blood analytes were found to be predictive for neurological outcome measures relating to motor function at either 3 or 12 months post-injury. Clinical variables such as age, level of injury, vertebral fracture, CCS, drinking, and smoking were also found to have a significant influence on the various outcome measures in the predictive models (Table S3).

Similarly, when factors from PCA-C were used in the predictive model, "liver function" and "acute inflammation and liver function" were again predictive at 3 months for sensory neurological outcome, with "acute inflammation and liver function" still being predictive at 1 year, but only for the pain outcome score (Table 5). Additionally, at 1 year, the "liver function" factor was predictive for Total M (Table 5). The same clinical variables, as previously found in the predictive model using the individual initial neurology scores (Table S3), were found to have a significant influence on the various outcome measures when the combined AIS neurology scores were used (Table 5). The significant contribution of the "liver function" and "acute inflammation and liver function" factors to the predictive models in Tables 5 and $\mathrm{S} 3$ ranged from $R^{2}$ of 0.013 to $R^{2}$ of 0.025 , with the greatest $R^{2}(0.025)$ occurring in the predictive model for 1 year pain outcome neurology (Table 5). In some models both "liver function" and "acute inflammation and liver function" factors were predictive; the best combined $R^{2}$ improvement $(0.043)$ from these factors was observed in the predictive model for 3 month pain (Table 5).

Although the number of participants was too small to adequately power an assessment of the predictive utility of the individual blood analytes, when the individual blood analytes were input into the predictive model alongside initial combined neurology scores and clinical variables to predict the combined AIS outcome neurology at 3 and 12 months, there were some individual blood analytes that significantly predicted outcome neurology (Table S4). ALT, magnesium, and GGT were predictive for 3 month AIS motor score with ALT remaining predictive at 1 year for AIS motor. Total bilirubin was also found to be predictive at 1 year for AIS motor, whereas only calcium was predictive for AIS sensory score at 3 months. Other clinical factors found to be predictive for outcome neurology are indicated in Table S4.

\section{Discussion}

In this study, we have analyzed a plethora of routinely gathered blood analyte data in a cohort of SCI patients and compared this to longitudinal neurological outcome measures following SCI. In order to use multiple regression analysis as a reliable predictive tool, one needs at least 10-20 times as many observations as there are independent variables, otherwise there can be "overfitting" of the data. As there were 30 blood analytes in this study, and only 82 patients (ideally $\geq 300$ patients would have been used), PCA was conducted to see whether the blood and neurology measures could be reduced into factors enabling a more robust predictive model to be generated from the data. This meant that the contributions of some blood analytes to the factors were not included, and their individual contribution to the predictive model was not fully addressed. We anticipate that future studies, with increased patient numbers, will have the capability to fully elucidate the impact of all the individual blood analytes routinely measured in SCI patients. The purpose of the current study was to provide an indication as to which blood analytes may have the most potential for future use in predictive neurological outcome models. 


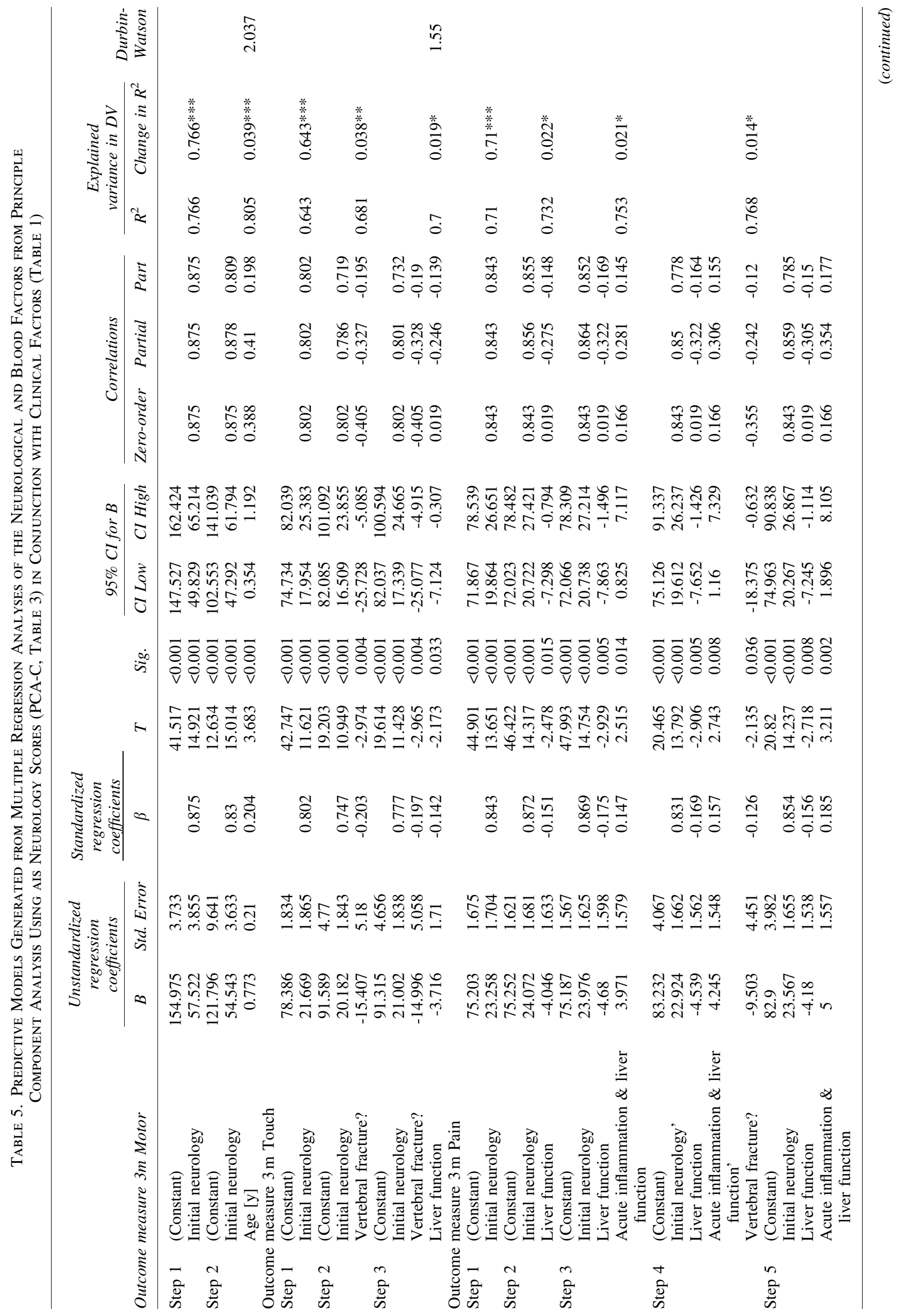




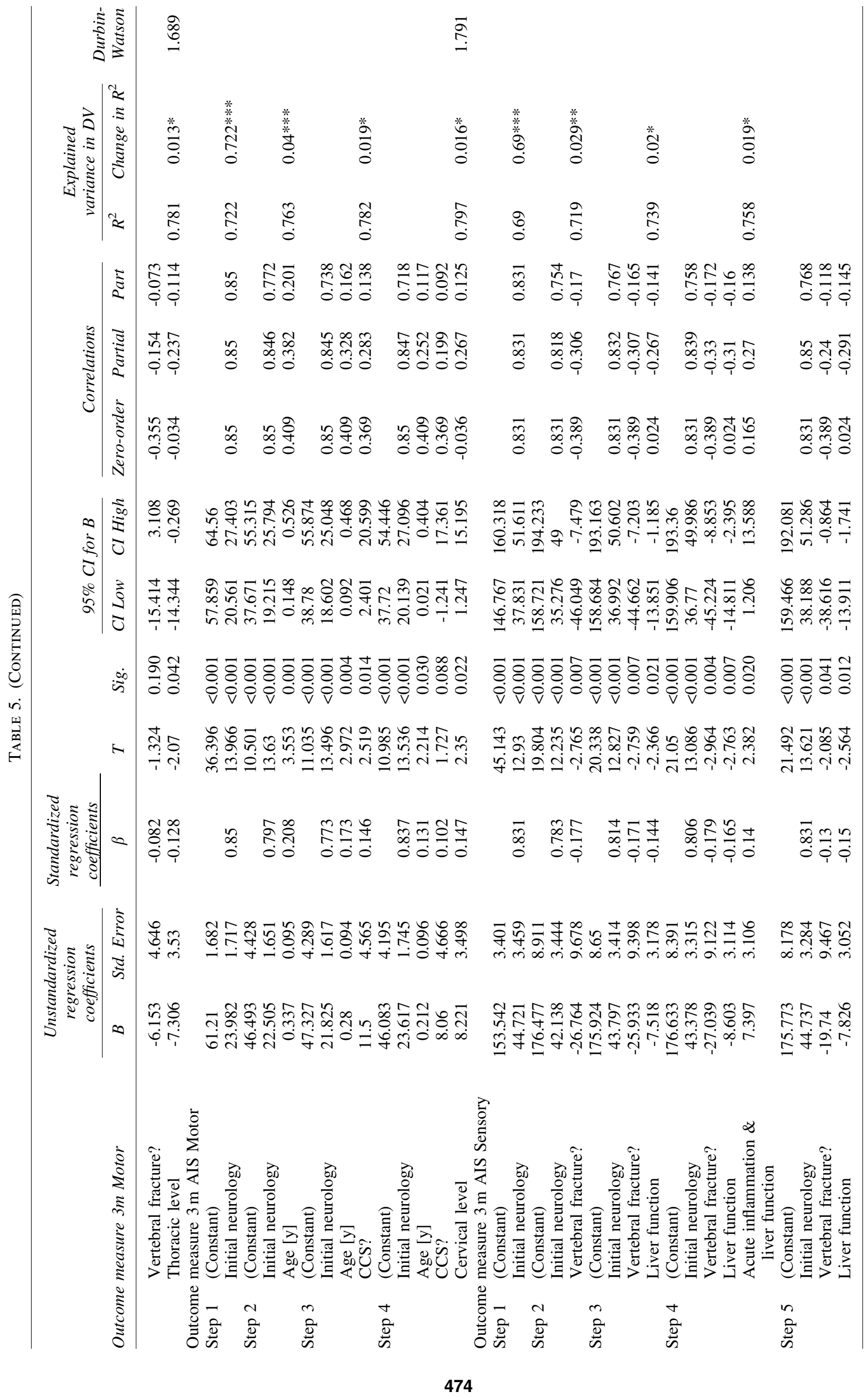




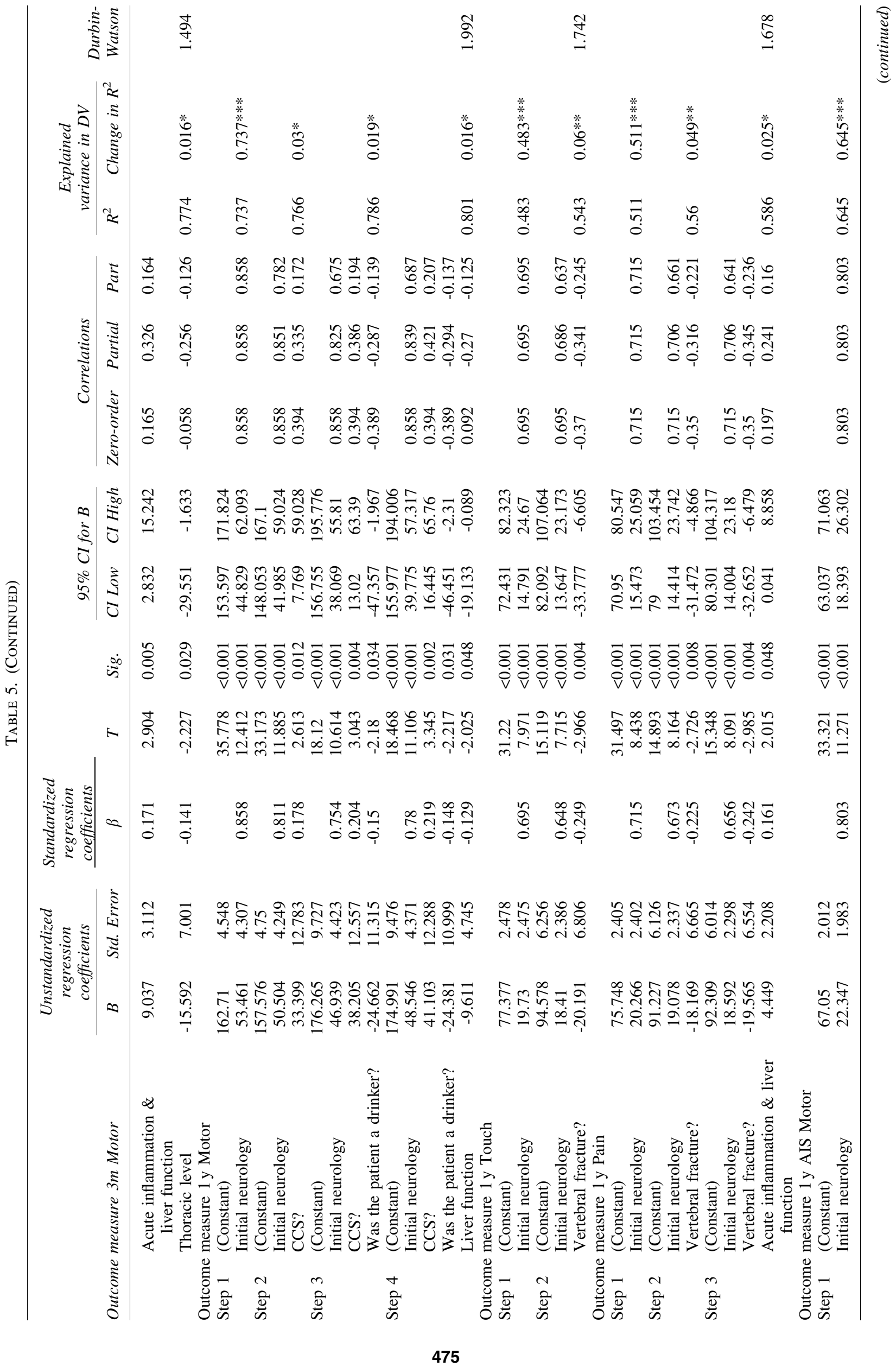




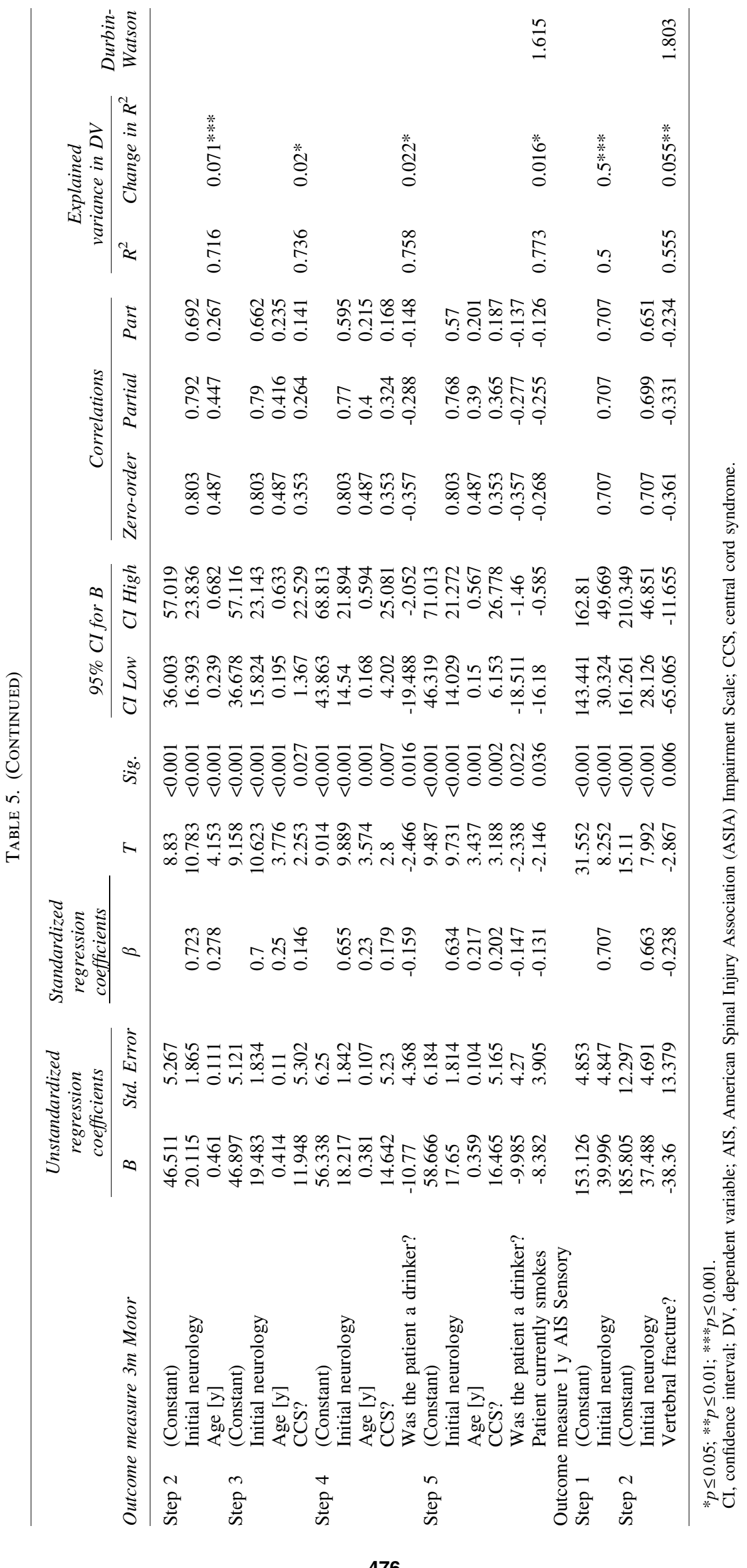


With respect to correlations between measures and outcomes, previous studies have linked hypokalemia with trauma. ${ }^{26}$ Therefore, our observed correlation between potassium and total motor score at 3 months is not unexpected. In a previous study involving 591 SCI patients, albumin was suggested to be an independent marker of long-term neurological outcome, ${ }^{27}$ which may explain the correlation with 3 month outcome measures (except for pain scores). Other literature has also found notable alterations to RBC, hemoglobin, and hematocrit values in non-traumatic SCI, and has found that lymphocytes decreased over time in traumatic SCI. ${ }^{28}$ Interestingly, none of the components of the "liver function" and "acute inflammation and liver function" factors, which were the only factors to add predictive value to the outcome models in this study, directly correlated with any outcome measures. This highlights the importance of taking into account clinical factors that might impact the patient's outcome neurology and blood measures in generating a predictive model. An ideal predictive model for outcome neurology in SCI patients would also take into account the patient's body mass index (BMI) and perhaps other information such as "dry" biomarker data garnered from clinical imaging.

The predictive model generated in our study based on the PCA analysis found that the "liver function" factor, which is made up of AP, ALT, and GGT, and the "acute inflammation and liver function" factor, composed of CRP and total bilirubin, added prognostic value to this model. However, it needs to be noted that although these factors added significant value to the models, the greatest $R^{2}$ achieved was only $4 \%$. Nonetheless, it appears that blood analytes related to liver function may have the potential to significantly predict neurological outcome for SCI patients. In particular, when we ran the model with the individual analytes, one of the contributing analytes in the "liver function" factor, ALT, appeared to be the most predictive $\left(R^{2}=15 \%\right)$ of the blood measures, although it must be stressed that this analysis is not statistically robust, because of the small cohort sample size. It may be possible that the lack of patients in this study, and hence the use of PCA, may have reduced the effects of individual analytes. In fact, the PCA resulted in some blood analytes not being considered in the predictive model. The findings of this study will form the basis of a future study in which a considerably larger data set $(\sim 500$ patients) is being collected. In this follow-on study, PCA may not be necessary, and the analytes will be assessed individually for their predictive potential.

ALT is an enzyme released from damaged hepatocytes, and is a key clinical marker of fatty liver disease. ${ }^{29}$ This study found it to be the only routine blood measure to predict neurological outcome in the form of AIS motor score at both 3 and 12 months (Table S4). Further, when grouped by PCA, "liver function" markers (AP, ALT, GGT) were predictive of neurological outcome, as were total bilirubin and CRP in the second predictive group "acute inflammation and liver function." SCI is known to lead to a systemic inflammatory response that can result in secondary organ complications, particularly in the liver, lungs, and kidneys. ${ }^{30-33}$ In addition, a rat contusion model study found ALT to be significantly raised in the 21 days following injury, coupled with excess lipid accumulation and increased expression of pro-inflammatory genes. ${ }^{34}$ Interestingly, this study also detected liver inflammation following lumbar $\mathrm{SCI}^{34}{ }^{34}$ whereas previous studies in rats had shown that liver inflammation can occur within 30 min of SCI, ${ }^{35}$ and that its severity correlates with level of injury. ${ }^{31} \mathrm{AP}$, another analyte of the predictive "liver function" factor, is an enzyme that plays a significant role in bone mineralization, and has four isoenzymes, which are intestinal (IAP), placental (PLAP), germinal
(GCAP), and tissue nonspecific (TNAP).$^{36-40}$ TNAP is the most abundant isoenzyme in the blood and is primarily derived from the bone, kidneys, and liver, but is also found in neuronal tissue. ${ }^{41}$ Higher levels of AP have been associated with the presence of heterotopic ossification (HO) following $\mathrm{SCI},{ }^{42}$ although other, smaller studies have found no association. ${ }^{43,44} \mathrm{HO}$ occurs in $\sim 20 \%$ of SCI patients, ${ }^{45}$ and its presence may impact on both rehabilitation and outcome measures for the patient. No note of this clinical feature was made during this study, but HO potentially needs to be recorded for future blood biomarker studies. TNAP has been shown to be elevated in Alzheimer's disease and in brain injury patients. ${ }^{46,47}$ A TBI study using a rat blast and weight drop model found that the injury resulted in a decrease in TNAP expression and activity in the brain and plasma at 6 and $24 \mathrm{~h}$ post- injury. ${ }^{48}$ Further, exogenous administration of AP has been shown to be beneficial, including improvements to renal function, for inflammatory disorders, such as sepsis, in humans and in murine models, and hence is worthy of further investigation in SCI patients. ${ }^{49,50}$

GGT, the final component of the predictive "liver function" factor, is a liver enzyme found on the plasma membrane of most cells and organ tissues, and it is frequently used as a marker for liver disease and more recently, many other conditions such as cardiovascular disease. ${ }^{51-53}$ Little is known of the possible role of GGT following SCI, but positive correlations between GGT and age, BMI, smoking, and alcohol consumption have been identified. ${ }^{54,55}$ In vivo and in vitro studies have also found overexpression of GGT to have a harmful effect on bone metabolism by accelerating bone reabsorption and causing osteoporosis. ${ }^{56,57}$ Another study analyzed the serum of 2415 Finnish men with good cognitive function, and found GGT to be positively associated with future risk of dementia. ${ }^{58}$ It has been proposed that GGT may contribute to dementia risk and poorer bone metabolism because of its pro-inflammatory and pro-oxidative properties. ${ }^{59}$ Future studies could compare GGT levels before and after SCI to establish whether elevated GGT before injury is associated with worse recovery.

The second factor found to have prognostic value from the PCA analysis was the "acute inflammation and liver function" factor, which consists of total bilirubin and CRP. Bilirubin is the breakdown product of heme and circulates in plasma conjugated to albumin until it is processed by hepatocytes and ultimately excreted from the body. The aforementioned systemic inflammation that follows traumatic SCI and impacts liver function is likely to influence blood bilirubin levels. ${ }^{30-32} \mathrm{CRP}$ is one of the key proteins in the acute inflammatory response. ${ }^{60}$ However, CRP is more specifically known to be indicative of acute infection, as opposed to the chronic low-grade inflammation associated with atherosclerosis, for example. ${ }^{61-63}$ CRP levels have been shown to be elevated in SCI patients in the absence of infection and regardless of injury level or duration, when compared with able-bodied controls. ${ }^{64}$ Other pro-inflammatory cytokines such as tumor necrosis factor alpha (TNF- $\alpha$ ) have been found to be elevated in the serum of SCI patients compared with uninjured controls during the subacute phase of injury (2-52 weeks post-injury). ${ }^{65}$ Further, patients who had lower TNF- $\alpha$ at $9 \mathrm{~h}$ post-injury experienced improved neurological function compared with SCI patients with higher TNF- $\alpha .{ }^{66}$ These results suggest that inflammatory markers may hold prognostic value for the neurological progression of SCI.

As four out of the five analytes that make up the two PCA components that were found to be predictive of neurological outcome are markers of liver function, and the remaining analyte is reflective of inflammatory status, this suggests that the liver may play a greater role in recovery following SCI than has been 
previously appreciated. However, a limitation of this study is the relatively small sample size of 82 patients. In order to perform more robust modelling of the data such that a reliable prognostic model can be built, further studies with increased patient numbers are required. ${ }^{67}$ Additionally, future studies may wish to incorporate additional data, such as obesity, omics (proteomics, metabolomics transcriptomics), and clinical imaging, which may help enhance the models' predictive strength. The low-grade systemic inflammation associated with obesity in particular, may be an important confounding variable for additional prognostic models. ${ }^{68-70}$ In future larger studies, the focus will be on improving neurological outcome prediction, which is likely to be most useful for patients with AIS B and C SCI, because of the decreased power of the initial AIS score in predicting outcome in these subsets of SCI patients. ${ }^{71}$ Further, there is scope to assess whether adjusting some of these routine measures improves outcomes for SCI patients. However, whether a targeted approach to alter the levels of these molecules can cause a concurrent change in a SCI patient's neurological outcome remains to be assessed, in appropriate randomized controlled clinical trials.

\section{Conclusion}

The results from this preliminary study suggest that routine blood analytes when statistically incorporated into "linked" factors can provide prognostic value for AIS motor and sensory score in SCI patients at 3 and 12 months post-injury. In particular, markers of liver function were found to add the most predictive value. This indicates that maintaining a healthy liver function acutely following SCI may be a key rehabilitative target in order to achieve optimal neurological recovery in the long term. These findings need to be corroborated with a larger cohort of SCI patients before a prognostic model of this type can be suggested for clinical use.

\section{Acknowledgments}

We acknowledge the hematology laboratory team based at the Robert Jones and Agnes Hunt Orthopaedic Hospital for their assistance in providing details regarding hematological and biochemical methodologies. We thank Matthew Ockendon for advice in the initial phases of the study. Dr. Jan-Herman Kuiper and Paul Cool have reviewed the data and have confirmed that appropriate statistical analyses have been performed throughout the study. We also thank the Institute of Orthopaedics and the Midland Centre for Spinal Injuries, also based at the Robert Jones and Agnes Hunt Orthopaedic Hospital for funding this study, and The EPSRC for funding GMBH.

\section{Author Disclosure Statement}

No competing financial interests exist.

\section{Supplementary Material}

Supplementary Table S1

Supplementary Table S2

Supplementary Table S3

Supplementary Table S4

\section{References}

1. Kuhle, J., Gaiottino, J., Leppert, D., Petzold, A., Bestwick, J., Malaspina, A., Lu, C., Dobson, R., Disanto, G., Norgren, N., Nissim, A.,
Kappos, L., Hurlbert, J., Yong, V., Giovannoni, G., and Casha, S. (2015). Serum neurofilament light chain is a biomarker of human spinal cord injury severity and outcome. J. Neurol. Neurosurg. Psychiatry $86,273-279$.

2. Ueno, T., Ohori, Y., Ito, J., Hoshikawa, S., Yamamoto, S., Nakamura, K., Tanaka, S., Akai, M., Tobimatsu, Y., and Ogata, T. (2011). Hyperphosphorylated neurofilament NF-H as a biomarker of the efficacy of minocycline therapy for spinal cord injury. Spinal Cord 49, 333336.

3. Ahadi, R., Khodagholi, F., Daneshi, A., Vafaei, A., Mafi, A., and Jorjani, M. (2015). Diagnostic value of serum levels of GFAP, pNF-H, and NSE compared with clinical findings in severity assessment of human traumatic spinal cord injury. Spine (Phila Pa 1976) 40, E823E830.

4. Roerig, A., Carlson, R., Tipold, A., and Stein, V. (2013). Cerebrospinal fluid tau protein as a biomarker for severity of spinal cord injury in dogs with intervertebral disc herniation. Vet. J. 197, 253258.

5. Hulme, C., Brown, S., Fuller, H., Riddell, J., Osman, A., Chowdhury, J., Kumar, N., Johnson, W., and Wright, K. (2017). The developing landscape of diagnostic and prognostic biomarkers for spinal cord injury in cerebrospinal fluid and blood. Spinal Cord 55, 114-125.

6. Fawcett, J., Curt, A., Steeves, J., Coleman, W., Tuszynski, M., Lammertse, D., Bartlett, P., Blight, A., Dietz, V., Ditunno, J., Dobkin, B., Havton, L., Ellaway, P., Fehlings, M., Privat, A., Grossman, R., Guest, J., Kleitman, N., Nakamura, M., Gaviria, M., and Short, D. (2007) Guidelines for the conduct of clinical trials for spinal cord injury as developed by the ICCP panel: spontaneous recovery after spinal cord injury and statistical power needed for therapeutic clinical trials. Spinal Cord 45, 190-205.

7. DeVivo, M., Kartus, P., Rutt, R., Stover, S., and Fine, P. (1990) The influence of age at time of spinal cord injury on rehabilitation outcome. Arch. Neurol. 47, 687-691.

8. Dragsted, L., Gao, Q., Praticò, G., Manach, C., Wishart, D., Scalbert, A., and Feskens, E. (2017). Dietary and health biomarkers-time for an update. Genes Nutr. 12, 24.

9. Wu, X., Yang, X., Shan, R., Li, T., Zi, T., Li, Y., Na, L., and Sun, C. (2017). Potential mediating biomarkers underlying the association of body mass index or waist circumference with blood pressure: results from three population-based studies. Sci. Rep. 7, 5364.

10. Dorcely, B., Katz, K., Jagannathan, R., Chiang, S., Oluwadare, B., Goldberg, I., and Bergman, M. (2017). Novel biomarkers for prediabetes, diabetes, and associated complications. Diabetes Metab. Syndr. Obes. 10, 345-361.

11. Kuo, T., and Chen, C. (2017). Bone biomarker for the clinical assessment of osteoporosis: recent developments and future perspectives. Biomark. Res. 5, 18.

12. Nallagangula, K., Nagaraj, S., Venkataswamy, L., and Chandrappa, M. (2017). Liver fibrosis: a compilation on the biomarkers status and their significance during disease progression. Future Sci. OA 4, FSO250.

13. Zhu, Z., Li, L., Ye, Z., Fu, T., Du, Y., Shi, A., Wu, D., Li, K., Zhu, Y., Wang, C., and Fan, Z. (2017). Prognostic value of routine laboratory variables in prediction of breast cancer recurrence. Sci. Rep. 7, 8135

14. Isenschmid, C., Kalt, J., Gamp, M., Tondorf, T., Becker, C., Tisljar, K., Locher, S., Schuetz, P., Marsch, S., and Hunziker, S. (2018). Routine blood markers from different biological pathways improve early risk strat fication in cardiac arrest patients: Results from the prospective, observational COMMUNICATE study. Resuscitation $130,138-145$.

15. Greco, I., Day, N., Riddoch-Contreras, J., Reed, J., Soininen, H., Kłoszewska, I., Tsolaki, M., Vellas, B., Spenger, C., Mecocci, P., Wahlund, L., Simmons, A., Barnes, J., and Lovestone, S. (2012). Alzheimer's disease biomarker discovery using in silico literature mining and clinical validation. J. Transl. Med. 10, 217.

16. Pan, S., Zhang, H., Rush, J., Eng, J., Zhang, N., Patterson, D., Comb, M., and Aebersold, R. (2005). High throughput proteome screening for biomarker detection. Mol. Cell Proteomics 4, 182-190.

17. Hsueh, M., Önnerfjord, P., and Kraus, V. (2014). Biomarkers and proteomic analysis of osteoarthritis. Matrix Biol. 39, 56-66.

18. Babu, M., Kaul, S., Dadheech, S., Rajeshwar, K., Jyothy, A., and Munshi, A. (2013). Serum albumin levels in ischemic stroke and its subtypes: correlation with clinical outcome. Nutrition 29, 872-875.

19. Bielewicz, J., Kurzepa, J., Czekajska-Chehab, E., Kamieniak, P., Daniluk, B., Bartosik-Psujek, H., and Rejdak, K. (2016). Worse 
neurological state during acute ischemic stroke is associated with a decrease in serum albumin levels. J. Mol. Neurosci. 58, 493-496.

20. Bernard, F., Al-Tamimi, Y., Chatfield, D., Lynch, A., Matta, B., and Menon, D. (2008). Serum albumin level as a predictor of outcome in traumatic brain injury: potential for treatment. J. Trauma 64, 872-875.

21. Fokkink, W., Walgaard, C., Kuitwaard, K., Tio-Gillen, A., van Doorn, P., and Jacobs, B. (2017). Association of albumin levels with outcome in intravenous immunoglobulin-treated Guillain-Barré syndrome. JAMA Neurol. 74, 189-196.

22. Chiò, A., Calvo, A., Bovio, G., Canosa, A., Bertuzzo, D., Galmozzi, F., Cugnasco, P., Clerico, M., De Mercanti, S., Bersano, E., Cammarosano, S., Ilardi, A., Manera, U., Moglia, C., Sideri, R., Marinou, K., Bottacchi, E., Pisano, F., Cantello, R., Mazzini, L., Mora, G., Piemonte and Valle d'Aosta Register for Amyotrophic Lateral Sclerosis. (2014). Amyotrophic lateral sclerosis outcome measures and the role of albumin and creatinine: a population-based study. JAMA Neurol. 71, 1134-1142.

23. Steyerberg, E., Mushkudiani, N., Perel, P., Butcher, I., Lu, J., McHugh, G., Murray, G., Marmarou, A., Roberts, I., Habbema, J., and Maas, A. (2008). Predicting outcome after traumatic brain injury: development and international validation of prognostic scores based on admission characteristics. PLoS Med. 5, e165.

24. Schuld, C., Franz, S., Brüggemann, K., Heutehaus, L., Weidner, N., Kirshblum, S., Rupp, R., and EMSCI study group. (2016). International standards for neurological classification of spinal cord injury: impact of the revised worksheet (revision 02/13) on classification performance. J. Spinal Cord Med. 39, 504-512.

25. Field, A. (2009). Discovering Statistics Using SPSS (and Sex and Drugs and Rock " $n$ ” Roll), 3rd ed. SAGE Publications Ltd.: London.

26. Beal, A., Scheltema, K., Beilman, G., and Deuser, W. (2002). Hypokalemia following trauma. Shock 18, 107-110.

27. Tong, B., Jutzeler, C., Cragg, J., Grassner, L., Schwab, J., Casha, S., Geisler, F., and Kramer, J. (2018). Serum albumin predicts long-term neurological outcomes after acute spinal cord injury. Neurorehabil. Neural Repair 32, 7-17.

28. Rouleau, P., and Guertin, P. (2010). Traumatic and non-traumatic spinal cord-injured patients in Quebec, Canada. Part 2: biochemical profile. Spinal Cord 48, 819-824.

29. Marchesini, G., Moscatiello, S., Di Domizio, S., and Forlani, G. (2008). Obesity-associated liver disease. J. Clin. Endocrinol. Metab. 93, S74-S80.

30. Campbell, S., Zahid, I., Losey, P., Law, S., Jiang, Y., Bilgen, M., van Rooijen, N., Morsali, D., Davis, A., and Anthony, D. (2008). Liver Kupffer cells control the magnitude of the inflammatory response in the injured brain and spinal cord. Neuropharmacology 55, 780-787.

31. Fleming, J., Bailey, C., Hundt, H., Gurr, K., Bailey, S., Cepinskas, G., Lawendy, A., and Badhwar, A. (2012). Remote inflammatory response in liver is dependent on the segmental level of spinal cord injury. J. Trauma Acute Care Surg. 72, 1194-1201.

32. Bao, F., Omana, V., Brown, A., and Weaver, L. (2012). The systemic inflammatory response after spinal cord injury in the rat is decreased by $\alpha 4 \beta 1$ integrin blockade. J. Neurotrauma 29, 1626-1637.

33. Gris, D., Hamilton, E., and Weaver, L. (2008). The systemic inflammatory response after spinal cord injury damages lungs and kidneys. Exp. Neurol. 211, 259-270.

34. Sauerbeck, A., Laws, J., Bandaru, V., Popovich, P., Haughey, N., and McTigue, D. (2015). Spinal cord injury causes chronic liver pathology in rats. J. Neurotrauma 32, 159-169.

35. Hundt, H., Fleming, J., Phillips, J., Lawendy, A., Gurr, K., Bailey, S., Sanders, D., Bihari, R., Gray, D., Parry, N., Bailey, C., and Badhwar, A. (2011). Assessment of hepatic inflammation after spinal cord injury using intravital microscopy. Injury 42, 691-696.

36. Barvencik, F., Beil, F., Gebauer, M., Busse, B., Koehne, T., Seitz, S., Zustin, J., Pogoda, P., Schinke, T., and Amling, M. (2011). Skeletal mineralization defects in adult hypophosphatasia - a clinical and histological analysis. Osteoporos. Int. 22, 2667-2675.

37. Millán, J., and Manes, T. (1988). Seminoma-derived Nagao isozyme is encoded by a germ-cell alkaline phosphatase gene. Proc. Natl. Acad. Sci. U.S.A. 85, 3024-3028.

38. Millan, J. (1986). Molecular cloning and sequence analysis of human placental alkaline phosphatase. J. Biol. Chem. 261, 3112-3115.

39. Weiss, M., Henthorn, P., Lafferty, M., Slaughter, C., Raducha, M., and Harris, H. (1986). Isolation and characterization of a cDNA encoding a human liver/bone/kidney-type alkaline phosphatase. Proc. Natl. Acad. Sci. U.S.A. 83, 7182-7186.
40. Berger, J., Garattini, E., Hua, J., and Udenfriend, S. (1987). Cloning and sequencing of human intestinal alkaline phosphatase cDNA. Proc. Natl. Acad. Sci. U.S.A. 84, 695-698.

41. Brun-Heath, I., Ermonval, M., Chabrol, E., Xiao, J., Palkovits, M. Lyck, R., Miller, F., Couraud, P., Mornet, E., and Fonta, C. (2011). Differential expression of the bone and the liver tissue non-specific alkaline phosphatase isoforms in brain tissues. Cell Tissue Res. 343 , 521-536.

42. Ploumis, A., Donovan, J.M., Olurinde, M.O., Clark, D.M., Wu, J.C., Sohn, D.J., and O'Connor, K.C. (2015). Association between alendronate, serum alkaline phosphatase level, and heterotopic ossification in individual with spinal cord injury. J. Spinal Cord Med. 38, 193-198.

43. Singh, R.S., Craig, M.C., Katholi, C.R., Jackson, A.B., and Mountz, J.M. (2003). The predictive value of creatine phosphokinase and alkaline phosphatase in identification of heterotopic ossification in patients after spinal cord injury. Arch. Phys. Med. Rehabil. 84, 1584-1588.

44. Kim, S.W., Charter, R.A., Chai, C.J., Kim, S.K., and Kim, E.S. (1990). Serum alkaline phosphatase and inorganic phosphorus values in spinal cord injury patients with heterotopic ossification. Paraplegia. 28, 441447.

45. Sullivan, M.P., Torres, S.J., Mehta, S., and Ahn, J. (2013). Heterotopic ossification after central nervous system trauma: A current review. Bone Joint Res. 2, 51-57.

46. Vardy, E., Kellett, K., Cocklin, S., and Hooper, N. (2012). Alkaline phosphatase is increased in both brain and plasma in Alzheimer's disease. Neurodegener. Dis. 9, 31-37.

47. Yamashita, M., Sasaki, M., Mii, K., Tsuzuki, M., Takakura, K., Yoshinoya, S., and Ohkubo, A. (1989). Measurement of serum alkaline phosphatase isozyme I in brain-damaged patients. Neurol. Med. Chir. (Tokyo) 29, 995-998.

48. Arun, P., Oguntayo, S., Albert, S., Gist, I., Wang, Y., Nambiar, M., and Long, J. (2015). Acute decrease in alkaline phosphatase after brain injury: a potential mechanism for tauopathy. Neurosci. Lett. 609, 152158.

49. Heemskerk, S., Masereeuw, R., Moesker, O., Bouw, M., van der Hoeven, J., Peters, W., Russel, F., Pickkers, P., and APSEP Study Group. (2009). Alkaline phosphatase treatment improves renal function in severe sepsis or septic shock patients. Crit. Care Med. 37, 417423.

50. Ebrahimi, F., Malo, M., Alam, S., Moss, A., Yammine, H., Ramasamy, S., Biswas, B., Chen, K., Muhammad, N., Mostafa, G., Warren, H., Hohmann, E., and Hodin, R. (2011). Local peritoneal irrigation with intestinal alkaline phosphatase is protective against peritonitis in mice. J. Gastrointest. Surg. 15, 860-869.

51. Mason, J., Starke, R., and Van Kirk, J. (2010). Gamma-glutamyl transferase: a novel cardiovascular risk biomarker. Prev. Cardiol. 13, 36-41.

52. Whitfield, J. (2001). Gamma glutamyl transferase. Crit. Rev. Clin Lab. Sci. 38, 263-355.

53. Fan, Y., Jin, X., Man, C., and Gong, D. (2018). Association of serum gamma-glutamyltransferase with chronic kidney disease risk: a metaanalysis. Free Radic. Res. 52, 819-825.

54. Nilssen, O., Førde, O., and Brenn, T. (1990). The Troms $\varnothing$ study: Distribution and population determinants of gamma-glutamylransferase. Am. J. Epidemiol. 132, 318-326.

55. Nilssen, O., and Førde, O. (1994). Seven-year longitudinal population study of change in gamma-glutamyltransferase: the Troms $\varnothing$ Study. Am. J. Epidemiol. 139, 787-792.

56. Niida, S., Kawahara, M., Ishizuka, Y., Ikeda, Y., Kondo, T., Hibi, T., Suzuki, Y., Ikeda, K., and Taniguchi, N. (2004). Gammaglutamyltranspeptidase stimulates receptor activator of nuclear factor$\kappa \mathrm{B}$ ligand expression independent of its enzymatic activity and serves as a pathological bone-resorbing factor. J. Biol. Chem. 279, 5752-5756.

57. Hiramatsu, K., Asaba, Y., Takeshita, S., Nimura, Y., Tatsumi, S., Katagiri, N., Niida, S., Nakajima, T., Tanaka, S., Ito, M., Karsenty, G., and Ikeda, K. (2007). Overexpression of $\gamma$-glutamyltransferase in transgenic mice accelerates bone resorption and causes osteoporosis. Endocrinology 148, 2708-2715.

58. Kunutsor, S., and Laukkanen, J. (2016). Gamma glutamyltransferase and risk of future dementia in middle-aged to older Finnish men: A new prospective cohort study. Alzheimers Dement. 12, 931-941.

59. Emdin, M., Pompella, A., and Paolicchi, A. (2005). Gammaglutamyltransferase, atherosclerosis, and cardiovascular disease: triggering oxidative stress within the plaque. Circulation 112, 2078-2080. 
60. Medzhitov, R. (2008). Origin and physiological roles of inflammation. Nature 454, 428-435.

61. Manns, P., McCubbin, J., and Williams, D. (2005). Fitness, inflammation, and the metabolic syndrome in men with paraplegia. Arch. Phys. Med. Rehabil. 86, 1176-1181.

62. Frost, F., Roach, M., Kushner, I., and Schreiber, P. (2005). Inflammatory C-reactive protein and cytokine levels in asymptomatic people with chronic spinal cord injury. Arch. Phys. Med. Rehabil. 86, 312-317.

63. Libby, P., Ridker, P., and Maseri, A. (2002). Inflammation and atherosclerosis. Circulation 105, 1135-1143.

64. Wang, T., Wang, Y., Huang, T., Su, T., Pan, S., and Chen, S. (2007). Circulating levels of markers of inflammation and endothelial activation are increased in men with chronic spinal cord injury. J. Formos. Med. Assoc. 106, 919-928.

65. Davies, A., Hayes, K., and Dekaban, G. (2007). Clinical correlates of elevated serum concentrations of cytokines and autoantibodies in patients with spinal cord injury. Arch. Phys. Med. Rehabil. 88, 13841393.

66. Biglari, B., Swing, T., Child, C., Büchler, A., Westhauser, F., Bruckner, T., Ferbert, T., Jürgen Gerner, H., and Moghaddam, A. (2015). A pilot study on temporal changes in IL- $1 \beta$ and TNF- $\alpha$ serum levels after spinal cord injury: the serum level of TNF- $\alpha$ in acute SCI patients as a possible marker for neurological remission. Spinal Cord $53,510-514$.
67. Holländer, N., and Sauerbrei, W. (2007). On statistical approaches for the multivariable analysis of prognostic marker studies, in: Advances in Statistical Methods for the Health Sciences. Statistics for Industry and Technology. J-L. Auget, N. Balakrishnan, M. Mesbah, and G. Molenberghs (eds.). Birkhäuser Publishing Ltd: Boston, pps. 19-38.

68. Deng, T., Lyon, C., Bergin, S., Caligiuri, M., and Hsueh, W. (2016). Obesity, inflammation, and cancer. Annu. Rev. Pathol. 11, 421-449.

69. Spyridaki, E., Avgoustinaki, P., and Margioris, A. (2016). Obesity, inflammation and cognition. Curr. Opin. Behav. Sci. 9, 169-175.

70. Saltiel, A., and Olefsky, J. (2017). Inflammatory mechanisms linking obesity and metabolic disease. J. Clin. Invest. 127, 1-4.

71. Roberts, T., Leonard, G., and Cepela, D. (2017). Classifications in brief: American Spinal Injury Association (ASIA) impairment scale. Clin. Orthop. Relat. Res. 475, 1499-1504.

Address correspondence to: Karina T. Wright PhD, ISTM Keele University RJAH Orthopaedic Hospital Oswestry, Shropshire United Kingdom

E-mail: karina.wright1@nhs.net 